\title{
Review of bone graft and bone substitutes with an emphasis on fracture surgeries
}

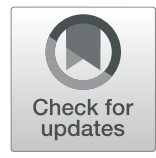

Hoon-Sang Sohn ${ }^{2}$ and Jong-Keon Oh ${ }^{1 *}$

\begin{abstract}
Background: Autogenous bone graft is the gold standard bone graft material. However, due to limitations of supply and morbidity associated with autograft harvest, various bone substitutes have been considered. This article aims to review the properties of the bone graft and various bone substitutes currently available in orthopedic surgery.

Main body: Synthetic bone substitutes consist of hydroxyapatite, tricalcium phosphate, calcium sulfate, or a combination of these minerals. Synthetic porous substitutes share several advantages over allografts, including unlimited supply, easy sterilization, and storage. However, they also have some disadvantages, such as brittle properties, variable rates of resorption, and poor performance in some clinical conditions. Recently, attention has been drawn to osteoinductive materials, such as demineralized bone matrix and bone morphogenetic proteins.

Conclusion: Despite tremendous efforts toward developing autograft alternatives, a single ideal bone graft substitute has not been developed. The surgeon should understand the properties of each bone graft substitute to facilitate appropriate selection in each specific clinical situation.
\end{abstract}

Keywords: Bone graft, Bone substitutes, Bone morphogenetic protein

\section{Background}

Bone graft procedures have been increasingly used in traumatology, tumor surgery, spine surgery, infection, and revision arthroplasty. In the US, approximately 500,000 bone graft procedures are performed annually [1]. These numbers easily double or triple on a global basis, resulting in a shortage in the availability of donor tissue conventionally used in these bone reconstruction procedures [1]. In terms of bone healing, autogenous bone graft exhibits the best osteogenic potential and is still considered to be a gold standard by many authors. Recently, another source of autogenous cancellous bone from intramedullary canal is developed. The reamer/irrigator/aspirator (RIA) technique was first developed to prepare long bones for intramedullary nail fixation $[2,3]$. However, the autogenous bone graft itself is an additional operation, and complications related to bone harvesting have been reported in up to $20.6 \%$ of cases [4-7]. Disadvantages of RIA include cortical perforation, eccentric reaming, articular perforation,

\footnotetext{
*Correspondence: jkoh@korea.ac.kr

${ }^{1}$ Department of Orthopaedic Surgery, Guro Hospital, Korea University College of Medicine, 80 Guro 2-dong, Guro-gu, Seoul 152-703, South Korea Full list of author information is available at the end of the article
}

and intra- and peri-operative fracture [2]. Allograft has several advantages, including easy use, improved safety profiles, time advantages, availability in diverse sizes and shapes, and no donor-site morbidity. For these reasons, it is a typical alternative to autogenous bone. However, in the process of sterilization and storage, the biological and mechanical properties change, which results in loss of osteoinduction and osteogenic capability. With more demands for spinal fusion, revision surgery of arthroplasty, and joint fusion, there is a relative deficiency in allogeneic bone donors. Due to these disadvantages of autogenous bone or allograft, the necessity of bone substitutes is increasing [1].

Bone healing is a multilateral process that requires mechanical stability and revascularization along with osteogenesis, osteoinduction, and osteoconduction. Osteoinduction means that primitive, undifferentiated and pluripotent cells are stimulated to develop into the bone-forming cell lineage [8]. Osteoconduction means that bone grows on a bone surface that permits bone growth on its surface or down into pores, channels or pipes [8]. Accordingly, the most ideal bone substitute should meet such conditions, have no risk of immunological rejection (biocompatible) or disease infection, and achieve incorporation of graft in host bone 
by gradually being substituted by regenerated bone [8]. It should be well molded into the bony defect within a short time and should be osteoinductive, osteoconductive, and resorbable [9]. In addition, the ideal bone substitute should be thermally nonconductive, sterilizable, and readily available at a reasonable cost [9].

Bone substitutes have a diversity of composition, mechanical strength, and functional biological mechanisms. Since each bone substitute has its own unique advantages and disadvantages, the relationship between various aspects of biological properties and bone healing should be understood. In this review, we will focus on the properties of bone graft and various bone substitutes currently available in orthopedic surgery.

\section{Bone graft Allograft}

Since the autogenous bone graft might lead to complications related to harvesting and its limitation in terms of graft amount from the patient, the allograft has served as an alternative. With the development of donor screening tests, the risk of infection has been minimized [10]. The advantages of bone allograft include no morbidity of the donor-site, unlimited use of material, and availability in mechanical support with various shapes and sizes. Bone allograft is most often preserved by a freeze-drying process and vacuum-packing. However, the concern that the mechanical property of bone allograft weakens and living osteogenic cells are removed in the process of sterilization and storage are disadvantages of the allograft. These processes affect the capacity of bone healing of the allograft and result in loss of osteogenic and osteoinductive function compared with the autogenous graft. Therefore, it is mainly used in osteoconduction by providing some mechanical support.

One of the important issues of allogeneic bone is that there is potential infection risks by virus and others agents despite thorough inspection of donors and plasma examination. However, only two cases of HIV infection were reported with a risk rate of 1:1.6 million $[11,12]$. Other cases of HBV, HCV and bacterial infections, including Clostridium difficilis, were also reported [13-16]. These types of infection cannot be removed completely even with various types of sterilization methods currently used. The risk of viral infection can be eliminated in freezing or freezing-drying process, which is the most frequently used technique in individual medical institutions [11, 17, 18]. Although a few people stressed that ethylene oxide gas can prevent viral infection, this gas is unable to penetrate cortical bone [19]. Other methods of sterilization, such as an irradiation, hydrochloric acid, and dimethyl sulfoxide, are unable to destroy a retrovirus similar to human immunodeficiency virus and feline leukemia virus [11].
The reason why the bone union rate following incorporation of allograft might be low is because the allograft has no osteogenesis and weak osteoinductivity and the process of sterilization and storage influence osteoconductivity and osteoinductivity [19-21]. Freezing or freeze-drying processes reduce the risk of an immune response of a bone graft after surgery, but sterilization itself weakens the mechanical property of a grafted bone up to approximately 50\%. Furthermore, given that a large amount of gamma irradiation or ethylene oxide gas considerably decreases the osteoinductivity of bone graft, the necessity of synthetic bone substitutes has emerged to avoid adverse effects.

Allogeneic bone is available in many preparations, including morselized and cancellous, corticocancellous, cortical graft, osteochondral, whole bone segment, and demineralized bone matrix. The integration process of allogeneic bone is similar to that nonvascularized autogenous bone graft normally undergoes, but the size of allograft influences the time of incorporation. This feature is partially related to a lack of cells in the donated region for bone healing and immune reaction arising in the integration process of allogeneic bone [18, 22, 23]. In most clinical cases, allogenic cancellous bone is used to treat the partial bone defect rather than a segmental bone defect or whole-bone defect because allo-cancellous bone has no mechanical stability. Clinically, it is commonly used to reinforce spinal fusion and pack the bone defect in revision arthroplasty in particular. Two well-known types of ossification reactions, intramembranous ossification and the enchondral ossification, occur on the surface of a graft bone. An external callus is created around allogeneic bone with bridging enchondral bone formation, and resorption and creeping substitution of cortical bone occur simultaneously. Thus, the two bones are attached as if welded [24]. In addition, fusion occurs only on the junction, and dead bone trabecular mostly remains in the innermost part of a grafted bone for several years [25]. At this time, bone strength is the weakest at the 3 rd to 6th month and slowly recovers during the 1 st to 2 nd year $[24,26]$.

\section{Demineralized bone matrix (DBM)}

DBM was first extracted from the human body in 1975 . It was introduced in orthopedics in 1980 [27]. DBM is made by a standardized process originally described by Urist et al. [28, 29], in which allobone is pulverized to a minute particle size $(74$ to $420 \mu \mathrm{m})$ followed by demineralization in $0.5 \mathrm{~N} \mathrm{HCL} \mathrm{mEq} / \mathrm{g}$ for 3 hours. The remaining acid is removed by rinsing in sterile water, ethanol, and ethyl ether. Through this process, type I collagen in cortical bone matrix and noncollagen proteins, including bone-inducing growth factors, such as BMP (bone morphogenetic proteins), transforming growth factor 
(TGF), insulin growth factor (IGF), and fibroblast growth factor (FGF), remain, but there is lack of mechanical support. Nevertheless, thanks to the extraction of these growth factors, DBM mainly acts as an osteoinductive material and possibly as an osteoinductive material compared with a general allograft, such as cancellous or cortical graft.

Although bone minerals are eliminated from allogenic bone, DBM is able to provide a 3-dimensional scaffold because the fibrous collagen structure of original tissues remains [30]. Since DBM is easily diluted and does not provide a mechanical packing effect for a bone defect lesion, its single use is limited, and DBM is manufactured with a variety of transmitters, including glycerol, hyaluronic acid, and calcium sulfate. Osteoinductivity of DBM is dependent on the levels of BMP-2 and BMP-7 as main growth factors. Various osteoinductivity potentials of individual DBM products are attributable to differences in DBM extraction and processing and a reduced amount of BMP in the process of sterilization and storage [31]. Although a product undergoes the same process, difference depending on the bone quality of allogeneic bone donor as a material are noted [32]. DBM has some expectations in terms of clinical use and efficacy, but research that supports its single use as a bone substitute is limited [33]. Accordingly, it is effective to add allogeneic cancellous bone or autogenous bone marrow. The most successful grafts may be composites of DBM and autogenous bone graft when used with stable fixation. DBM also has a potential risk of transmitted viral infection because it is an allogenic material. Currently, there is relevant research with a small number of randomized controlled trials. Therefore, to establish DBM as a reliable method for regular clinical use, it is necessary to produce long-term follow-up results and data.

\section{Bone substitutes}

The most ideal bone substitute should include the ability of providing a scaffold for osteoconductivity and growth factors for osteoinductivity and should be structurally similar to real bone. The scaffold for ideal osteoconductivity should exhibit osseointegration and a 3D structure suitable for growing cells and blood vessels. In addition, it should have good biocompatibility, biodegradation, and biomechanics similar to surrounding bone tissues. Numerous bone substitutes that satisfy these conditions are commercially available in orthopedics.

\section{Ceramic and ceramic composites}

Ceramic bone substitutes are typical calcium-based synthetic bone substitutes that are already approved in terms of stability and effect. Given the problems with autogenous bone and allogeneic bone, osteoconductive ceramic with biodegradation draws considerable attention these days. For synthesized graft to exert its biological effects, several conditions are required: compatibility with surrounding tissues, chemical stability in body fluid, biomechanical and physical compatibility, durability in sterilization process, reasonable price, and consistency of reliable quality [34]. Today, various types of ceramic products are composed of calcium phosphate, including hydroxyapatite (HA) and tricalciumphosphate (TCP), or (calcium sulfate), or their compounds [34, 35].

Ceramic features no limitations of quantity, no risk of morbidity and infection of the donor site, and easy sterilization and storage. However, primary application of ceramics is mainly focused on bone defects, such as fracture with joint depression, because ceramics are fragile and have poor mechanical strength. Since the amount of resorption of ceramic varies depending on material, if resorption does not occur properly, it could possibly impede bone remodeling. As a result, the speed of bony union and the process of remodeling to obtain a proper strength are delayed. In addition, due to its fragility, it is difficult to mold ceramic into a desired shape during operation. The remodeling process relies mainly on ceramic biodegradability. At this time, material that is not absorbed biologically impedes the remodeling process and becomes a region of mechanical stress concentration [35]. Too slow absorption impedes bone remodeling, and too fast absorption reduces mechanical stability and causes fibrous tissue formation instead of osteogenesis [36].

\section{Hydroxyapatite (HA)}

HA is bioactive ceramic and a main mineral of bone. Given its density, HA with a porous structure is easily bio-absorbable and exhibits good osteoconductivity. Therefore, when it is introduced in vivo, surrounding bone tissues grows and gradually progresses through the bone substitution. Regarding the material features of $\mathrm{HA}$, it can be inserted in line with a shape of a defective region. In addition, it is easily absorbed, does not generate metabolite impeding osteogenesis, and causes almost no foreign body reaction due to its excellent biocompatibility [25]. HA has very high compression and tensile strength compared with TCP. Since HA is slowly degraded and retained in vivo for a long period of time, it impedes bone remodeling extends the mechanical vulnerability of new bone, and remains as permanent stressor.

\section{Tri-calcium phosphate (TCP)}

Tri-calcium phosphate is osteoconductive calcium phosphate and has the most similar chemical composition to human bone. It has better absorption than hydroxyapatite (HA) [37, 38]. It is more porous than HA and features weak mechanical strength and fast absorption. More porous TCP undergoes biodegradation within 6 
weeks after its introduction into the bone defect. Since its compression and tensile strength is very similar to that of cancellous bone, it is used in regions with no mechanical load [39]. Moreover, TCP has better osteoconductivity and biocompatibility than conventional bone cement with PMMA, and it is possible to inject TCP with a syringe into a bone defect or the screw insertion site in case of fracture fixation [40]. As another main component, polyphosphate is highly concentrated in osteoblasts and is involved in mineralization of bone metabolism [6, 41]. In contrast of HA, ceramic TCP is biodegraded fast in vivo. It is biodegraded within 4-8 weeks after graft, and it is difficult to obtain proper bone formation during the early period [42]. In consideration of these properties, biphasic ceramic with a mixture of HA and TCP is manufactured. Depending on the mixture ratio of these two components, it is possible to adjust the speed and degree of absorption and mechanical strength [43-46].

\section{Calcium phosphate cement (CPC)}

The discovery of the first $\mathrm{CPC}$ occurred coincidentally via the observation of calcium phosphate solubility in 1986 [47]. CPC consists of calcium phosphate. Calcium phosphate cements (CPCs) are frequently used to repair bone defects. Currently, CPC are defined as a combination of one or more calcium phosphate powders which, upon mixing with a liquid phase, form a paste able to self-set and harden in situ in the bone defect site to form a scaffold [48]. A body-temperature dissolution-precipitation reaction is one of the most important characteristics of $\mathrm{CPC}$, which facilitates is ability to mold and fill the bone defect [48]. Injectability, one of the advantages of CPC, allows application of CPC in minimally invasive surgery [49]. Therefore, it is clinically used to fill metaphyseal or subchondral cortical defects caused by articular fracture. Since CPC has the material property of ceramic, bioabsorbable-enhancing additives, such as chitosan or Vicryl meshes, can be used to improve mechanical strength [50]. CPC has osteoconductivity; it is gradually absorbed in the bone remodeling process and is replaced by a new bone [39]. Currently, the paradigm has moved toward enhancement of biological interactions of CPC, such as bone tissue engineering, in addition to improvement in the mechanical strength of CPC and the addition of cells and growth factors in cement [7, 39, 51, 52]. In addition, 3D printing for fabricating CPC scaffolds is rapidly developing with a high degree of accuracy. Here, 3D printed CPC offers specific benefits for clinical applications, including easy adaptation and fixation, reduced surgical time, and good esthetic results [53, 54]. Furthermore, with recent advances in tissue engineering, "tissue regeneration by natural tissues" instead of "tissue replacement by biomaterials" has been proposed and emphasized. This new emphasis on tissue engineering is enhanced by CPC's excellent biological interaction such as osteoconductivity, osteoinductivity, biodegradability and bioactivity $[55,56]$.

\section{Calcium sulfate}

Calcium sulfate is clinically used to fill defects, such as bone cavities, and segmental bone defect, and moreover expansion use for spinal fusion and even for filling of harvest site of autogenous bone. Through recrystallization, it becomes a solid material and gives mechanical stability to its inserted region. Calcium sulfate normally undergoes biodegradation within 6-8 weeks after its insertion into the bone defect. Given its lack of porosity, calcium sulfate has limited osteoconductivity. Given its mechanical disadvantage and rapid resorption. Compared with calcium phosphate, calcium sulfate is not often used [39].

\section{Bone morphogenetic protein (BMP)}

Urist et al. reported that the growth factors extracted from bone organic component were able to induce osteogenesis and named them bone morphogenetic proteins (BMPs) [57, 58]. Many types of local growth factors are related to bone healing. Depending on similarities in composition, these growth factors are classified into approximately 20 multiprotein growth factor families or superfamilies. These growth factors include epidermal growth factor (EGF), insulin-like growth factor (IGF), fibroblast growth factor (FGF), platelet-derived growth factor (FDGF), and transforming growth factor (FGF). Among them, only BMPs that belong to the transforming growth factor superfamily are known to run all processes of new osteogenesis $[59,60]$. After penetration of mesenchymal cells, BMPs are involved in a series of processes, including differentiation to chondrocytes, removal of cartilage, and osteogenesis. Depending on their levels, BMPs have a steep dose-response curve. If a large amount of BMPs are injected, osteoinduction occurs early, and a considerable amount of bone is generated [61]. As the injection amount increases, direct osteogenesis is increased by intramembranous ossification rather than endochondral ossification. BMP-2, BMP-7 (OP-1), and BMP-6 have similar roles and activities in the process of osteogenesis [62, 63]. To obtain the same degree of osteoinduction, a little more BMP-5 is required. BMP-3 (Ostenogenin), which is the most distributed in bone, functions as negative modulator in osteogenesis [64].

There are a few studies with a small number of randomized controlled trials only. The US Food and Drug Administration approved the use of BMP-2 for open tibial shaft fracture as a selective clinical indication [65] and the use of BMP-7 for iliac nonunion and traumatic bone defect [66]. BMP is used as an adjuvant for the spinal lumbar. When BMP-2 was used together with an 
allograft, its fusion rate was similar to that of autogenous bone graft [67]. These BMPs account for only $0.1 \%$ of total bone proteins and are mainly found in cortical bone. Since BMPs exist in the extracellular matrix, it is impossible to obtain BMPs until the bone matrix is demineralized [28, 68]. Accordingly, to obtain several grams (g) of BMPs, several kilograms $(\mathrm{kg})$ of bones are needed. In addition, regardless of high-quality purity, they can include impurities, potentially causing unexpected reactions and results.

With the development of molecular cloning technology, these problems were solved by the creation of a large amount of recombinant human BMPs (rhBMP), which do not trigger immune reactions [69]. In the rhBMP- or bovine BMP-based animal test, these substances exhibited considerably good results. According to the research in which partially purified bovine BMPs were used for canine thoracic vertebrae fusion, the use of BMPs and autogenous bone together had the highest success rate $(71 \%)$ [70]. In the thoracic vertebrae fusion of canine posterolateral transverse processes with the use of rhBMP-2, it was possible to achieve faster fusion [68]. Using an excess amount of BMPs physiologically can trigger osteolysis [71]. Depending on patients and body regions, the requirement of BMPs varies. Regarding the side effect of BMPs in the cervical vertebrae, contraindications are reported [72]. Therefore, tissue engineering approaches for long-term control and local transmission of these growth factors are a promising research area. Tissue engineering related to bone grafts have been conducted to provide all the fundamental properties of an ideal bone graft; however, it has proven difficult to achieve vascularisation in grafts which are large enough for use in clinical applications $[55,73]$.

\section{Summary}

Of the graft materials for obtaining bone union, autogenous bone is the gold standard. However, there have been many shortages of autogenous bone material, and such situations are currently on the rise. To supplement autogenous bone, allogeneic bone is often used. However, depending on use conditions, the bone union rate of allogeneic bone is not satisfactory, and there is a potential for infectious diseases. For this reason, the development of synthetic materials such as ceramic has drawn a lot of attention and has been researched. Although ceramic has advantages such as easy production and no risk of infectious diseases, it has only osteoconductivity, causes mechanical vulnerability depending on material characteristics such as bioabsorption, and has difficulty playing its role continuously in the process of bone union. Currently, there is no material to completely replace autogenous bone, and it is not easy to select the best bone substitute. Therefore, in selecting the material, tissue survival capability, the size of bone defect, the size and shape of the graft material, biomechanical properties, ease of manipulation, cost, ethical issues, biological properties, and complications must be considered; biological and mechanical characteristics must be evaluated in each clinical situation.

\section{Acknowledgements \\ Not applicable \\ Funding \\ Not applicable \\ Availability of data and materials \\ Not applicable \\ Authors' contributions \\ HS Sohn and JK Oh were responsible for initial literature review and writing of the manuscript. Both HS Sohn and JK Oh contributed equally towards the completion of the manuscript. Both authors read and approved the final manuscript.}

Ethics approval and consent to participate

Not applicable

Consent for publication

Not applicable

\section{Competing interests}

The authors declare that they have no competing interest.

\section{Publisher's Note}

Springer Nature remains neutral with regard to jurisdictional claims in published maps and institutional affiliations.

\section{Author details}

'Department of Orthopaedic Surgery, Guro Hospital, Korea University College of Medicine, 80 Guro 2-dong, Guro-gu, Seoul 152-703, South Korea. ${ }^{2}$ Department of Orthopaedic Surgery, Wonju Severance Christian Hospital, Yonsei University Wonju College of Medicine, Wonju, South Korea.

Received: 14 October 2018 Accepted: 21 February 2019 Published online: 14 March 2019

References

1. Greenwald AS, Boden SD, Goldberg VM, Khan Y, Laurencin CT, Rosier RN. Bone-graft substitutes: facts, fictions, and applications. J Bone Joint Surg Am. 2001;83(Suppl 2 Pt 2):98-103.

2. Baldwin P, Li DJ, Auston DA, Mir HS, Yoon RS, Koval KJ. Autograft, allograft, and bone graft substitutes: clinical evidence and indications for use in the setting of orthopaedic trauma surgery. J Orthop Trauma. 2019. https://doi. org/10.1097/BOT.0000000000001420 [Epub ahead of print].

3. Billow D, Khlopas A, Chughtai M, Saleh A, Siqueira MB, Marinello P, et al. The reamer-irrigator-aspirator system: a review. Surg technol int 2016;26: 287-294.

4. Goulet JA, Senunas LE, DeSilva GL, Greenfield ML. Autogenous iliac crest bone graft. Complications and functional assessment. Clin Orthop Relat Res. 1997;339:76-81.

5. Pollock R, Alcelik I, Bhatia C, Chuter G, Lingutla K, Budithi C, et al. Donor site morbidity following iliac crest bone harvesting for cervical fusion: a comparison between minimally invasive and open techniques. Eur Spine J. 2008; 17(6):845-52.

6. Summers BN, Eisenstein SM. Donor site pain from the ilium. A complication of lumbar spine fusion. J Bone Joint Surg Br. 1989;71(4):677-80.

7. Seiler JG 3rd, Johnson J. lliac crest autogenous bone grafting: donor site complications. J South Orthop Assoc. 2000;9(2):91-7.

8. Kornberg A, Rao NN, Ault-Riché D. Inorganic polyphosphate: a molecule of many functions. Annu Rev Biochem. 1999;68:89-12. 
9. Campana V, Milano G, Pagano E, Barba M, Cicione C, Salonna G. Bone substitutes in orthopaedic surgery: from basic science to clinical practice. J Mater Sci Mater Med. 2014;25:2445-61.

10. Manyalich M, Navarro A, Koller J, Loty B, de Guerra A, Cornu O, et al. European quality system for tissue banking. Transplant Proc. 2009;41:2035-43.

11. Center for Disease Control. Transmission of HIV through bone transplantation: case report and publc health recommendation. JAMA. 1988;260:2487-8.

12. Buck B, Malinin T, Beown M. Bone transplantation and human immunodeficiency virus. Clin Orthop. 1989;240:129-36.

13. Khan SN, Cammisa FPJ, Sandhu HS, Diwan AD, Girardi FP, Lane JM. The biology of bone grafting. J Am Acad Orthop Surg. 2005;13(1):77-86.

14. Tomford WW. Transmission of disease through transplantation of musculoskeletal allografts. J Bone Joint Surg Am. 1995;77(11):1742-54.

15. Mroz TE, Joyce MJ, Steinmetz MP, Lieberman IH, Wang JC. Musculoskeletal allograft risks and recalls in the United States. J Am Acad Orthop Surg. 2008; 16(10):559-65.

16. Lomas R, Chandrasekar A, Board TN. Bone allograft in the UK: perceptions and realities. Hip Int. 2013;23(5):427-33.

17. Pelker R, Friedlaender $\mathrm{G}$. Biomechanical aspects of bone autografts and allografts. Orthop Clin North Am. 1987;18:235-9.

18. Hamer AJ, Strachan JR, Black MM, Ibbotson CJ, Stockley I, Elson RA. Biomechanical properties of cortical allograft bone using a new method of bone strength measurement: a comparison of fresh, fresh-frozen, and irradiated bone. J Bone Joint Surg Br. 1996;78:363-8.

19. Prolo $D$, Pedrotti $P$, White $D$. Ethyelene oxide sterilization of bone, duramater and fascia lata for human transplantation. Neurosurgery. 1980;6:529-39.

20. Herron L, Newman M. The failure of ethylene oxide gas sterilized freeze-dried bone graft for thoracic and lumbar spine fusion. Spine. 1989;14:496-500.

21. An HS, Simpson JM, Glover JM, Stephany J. Comparison between allograft plus demineralized bone matrix versus autograft in anterior cervical fusion. A prospective multicenter study. Spine. 1995;20:2211-6.

22. Stevenson S, Emery SE, Goldberg VM. Factors affecting bone graft incorporation Clin Orthop Relat Res. 1996:324:66-74.

23. Sandhu HS, Grewal HS, Parvataneni H. Bone grafting for spinal fusion. Orthop Clin North Am. 1999;30:685-98.

24. Enneking WF, Campanacci DA. Retrieved human allografts: a clinicopathological study. J Bone Joint Surg Am. 2001;83:971-86.

25. Finkemeier CG. Bone-grafting and bone-graft substitutes. J Bone Joint Surg Am. 2002;84:454-64.

26. Ullmark G, Obrant KJ. Histology of impacted bone-graft incorporation. J Arthroplast. 2002;17:150-7.

27. Urist M, Mikulski A, Boyd S. A chemosterilized antigenextracted autodigested alloimplant for bone banks. Arch Surg. 1975;110(4):416-28.

28. Urist MR, Silverman BF, Buring K, Dubuc FL, Rosenberg JM. The bone induction principle. Clin Orthop. 1967:53:243-83.

29. Urist MR, Dawson E. Intertransverse process fusion with the aid of chemosterilized autolyzed antigen-extracted allogenic (AAA) bone. Clin Orthop. 1981;154:97-113.

30. Lane JM. Bone morphogenic protein science and studies. J Orthop Trauma. 2005:19:S17-22.

31. Grabowski G, Cornett CA. Bone graft and bone graft substitutes in spine surgery: current concepts and controversies. J Am Acad Orthop Surg. 2013; 21:51-60.

32. Wildemann B, Kadow-Romacker A, Pruss A, Haas NP, Schmidmaier G Quantification of growth factors in allogenic bone grafts extracted with three different methods. Cell Tissue Bank. 2007:8:107-14.

33. Kinney RC, Ziran BH, Hirshorn K, Schlatterer D, Ganey T. Demineralized bone matrix for fracture healing: fact or fiction? J Orthop Trauma. 2010;24(Suppl 1):S52-5.

34. Boden S, Schimandle J. Biologic enhancement of spinal fusion. Spine. 1995; 20:113-23.

35. Flattley T, Lynch K, Benson M. Tissue response to implants of calcium phosphate ceramic in the rabbit spine. Clin Orthop. 1983;179:246-52.

36. Parikh SN. Bone graft substitutes in modern orthopedics. Orthopedics. 2002; 25:1301-9.

37. Eggli PS, Müller W, Schenk RK. Porous hydroxyapatite and tricalcium phosphate cylinders with two different pore size ranges implanted in the cancellous bone of rabbits. A comparative histomorphometric and histologic study of bony ingrowth and implant substitution. Clin Orthop Relat Res. 1988;232:127-38.
38. Klein CP, Driessen AA, de Groot K, van den Hooff A. Biodegradation behavior of various calcium phosphate materials in bone tissue. J Biomed Mater Res. 1983;17:769-84.

39. Zwingenberger S, Nich C, Valladares RD, Yao Z, Stiehler M, Goodman SB. Recommendations and considerations for the use of biologics in orthopedic surgery. BioDrugs. 2012;26:245-56.

40. Lindner T, Kanakaris NK, Marx B, Cockbain A, Kontakis G, Giannoudis PV. Fractures of the hip and osteoporosis: the role of bone substitutes. J Bone Joint Surg Br. 2009;91:294-303.

41. Schröder HC, Kurz L, Müller WE, Lorenz B. Polyphosphate in bone. Biochemistry (Mosc). 2000;65:296-303.

42. Ferrao J. Experimental evaluation of ceramic calcium phosphate as a substitute for bone grafts. Plast Reconstr Surg. 1979;63:634-40.

43. Moore D, Chapman M, Manske D. The evaluation of a biphasic calcium phosphate ceramic for use in grafting long-bone diaphyseal defect. J Orthop Res. 1987;5:356-65.

44. Daculsi G, LeGeros R, Nery E, Lynch K, Kerebel B. Transformation of biphasic calcium phosphate ceramics in vivo: ultrstructural and physicochemical characterization. J Biomed Mater Res. 1989;23:883-94.

45. Emery S, Fuller D, Stevenson S. Ceramic anterior spinal fusion: biological and biomechanical comparison in a canine model. Spine. 1996:21:2713-9.

46. Boden S, Martin G, Morone M, Ugbo J, Moskovitz P. Posterolateral lumbar intertrnasverse process spine arthrodesis with recombinant human bone morphogenetic protein-2/hydroxyapatite-tricalcium phosphate after laminectomy in the nonhuman primate. Spine. 1999;24:1179-85.

47. Brown WE, Chow LC. A new calcium phosphate, water setting cement. In: Brown PW, editor. Cements res Progress. Westerville: American ceramic Society; 1986. p. 352-79.

48. Ginebra MP, Canal C, Espanol M, Pastorino D, Montufar EB. Calcium phosphate cements as drug delivery materials. Adv Drug Deliv Rev. 2012;64:1090-110

49. Xu HH, Weir MD, Burguera EF, Fraser AM. Injectable and macroporous calcium phosphate cement scaffold. Biomaterials. 2006;27:4279-87.

50. Yokoyama A, Yamamoto S, Kawasaki T, Kohgo T, Nakasu M. Development of calcium phosphate cement using chitosan and citric acid for bone substitute materials. Biomaterials. 2002:23:1091-101.

51. Mestres G, Le Van C, Ginebra MP. Silicon-stabilized a-tricalcium phosphate and its use in a calcium phosphate cement: characterization and cell response. Acta Biomater. 2012;8:1169-79.

52. Weir MD, Xu HH. Osteoblastic induction on calcium phosphate cementchitosan constructs for bone tissue engineering. J Biomed Mater Res A. 2010;94:223-33.

53. Guvendiren M, Molde J, Soares RM, Kohn J. Designing biomaterials for 3D printing. ACS Biomater Sci Eng. 2016;2:1679-93.

54. Trombetta R, Inzana JA, Schwarz EM, Kates SL, Awad HA. 3D printing of calcium phosphate ceramics for bone tissue engineering and drug delivery. Ann Biomed Eng. 2017:45:23-44.

55. An J, Liao H, Kucko NW. Long-term evaluation of the degradation behavior of three apatite-forming calcium phosphate cements. J Biomed Mater Res A. 2016;104(5):1072-81.

56. Xu HH, Wang P, Wang L, Bao C, Chen Q, Weir MD, et al. Calcium phosphate cements for bone engineering and their biological properties. Bone Res. 2017:20(5):17056

57. Urist M. Bone: formation by autoinduction. Science. 1965;150:893-9.

58. Urist M, Strates B. Bone formation in implants of partially and wholly demineralized bone matrix. Clin Orthop. 1970;71:271-8.

59. Wozney JM, Rosen V, Celeste AJ, Mitsock LM, Whitters MJ, Kriz RW, et al. Novel regulators of bone formation. Molecular clones and activitiesScience. 1988;242:1528-34

60. Ozkaynak E, Schnegelsberg PN, Jin DF, Clifford GM, Warren FD, Drier EA, et al. Osteogenic protein-2: a new member of the transforming growth factorsuperfamily expressed early in embryogenesis. J Biol Chem. 1992;267:25220-7.

61. Wozney JM. Overview of bone morphogenetic proteins. Spine. 2002;27:2-8.

62. Gitelman SE, Kobrin MS, Ye JQ, Lopez AR, Lee A, Derynck R. Recombinant Vgr-1/BMP-6-expressing tumor induce fibrosis and enchondral bone formation in vivo. J Cell Biol. 1994;126:1595-609.

63. Sampath TK, Maliakal JC, Hauschka PV, Jones WK, Sasak H, Tucker RF, et al. Recombinant human osteogenic protein-1(hOP-1) induces new bone formation in vivo with a specific activity comparable with natural bovine osteogenic protein and stimulates osteoblast proliferation and differentiation in vitro. J Bio Chem. 1992;267:20352-62. 
64. Daluiski A, Engstrand T, Bahamonde ME, Gamer LW, Agius E, Stevenson SL, et al. Bone morphogenetic protein-3 is a negative regulator of bone density. Nat Genet. 2001;27:84-8.

65. Govender S, Csimma C, Genant HK, Valentin-Opran A, Amit Y, Arbel R, et al. Recombinant human bone morphogenetic protein-2 for treatment of open tibial fractures: a prospective, controlled, randomized study of four hundred and fifty patients. J Bone Joint Surg Am. 2002;84:2123-34.

66. Friedlaender GE, Perry CR, Cole JD, Cook SD, Cierny G, Muschler GF, et al. Osteogenic protein-1 (bone morphogenetic protein-7) in the treatment of tibial nonunions. J Bone Joint Surg Am. 2001;83(Suppl 1):S151-8.

67. Slosar PJ, Josey R, Reynolds J. Accelerating lumbar fusions by combining rhBMP-2 with allograft bone: a prospective analysis of interbody fusion rates and clinical outcomes. Spine J. 2007;7:301-7.

68. Sandhu HS, Kanim LE, Kabo JM, Toth JM, Zeegen EN, Liu D, et al. Effective doses of recombinant human bone morphogenetic protein-2 in experimental spinal fusion. Spine. 1996;21:2115-20.

69. Wozney J. The bone morphogenetic protein family and osteogenesis. Mol Reprod Dev. 1992;32:160-7.

70. Lovell TP, Dawson EG, Nilsson OS, Urist MR. Augmentation of spinal fusion with bone morphogenetic protein in dogs. Clin Orthop. 1987;234:266-74.

71. Baas J, Elmengaard B, Jensen TB, Jakobsen T, Andersen NT, Soballe K. The effect of pretreating morselized allograft bone with rhBMP-2 and/or pamidronate on the fixation of porous $\mathrm{Ti}$ and HA-coated implants. Biomaterials. 2008:29:2915-22.

72. Shields LB, Raque GH, Glassman SD, Campbell M, Vitaz T, Harpring J, et al. Adverse effects associated with high-dose recombinant human bone morphogenetic protein-2 use in anterior cervical spine fusion. Spine(PhilaPa 1976). 2006;31:542-7.

73. Fillingham Y, Jacobs J. Bone grafts and their substitutes. Bone Joint J. 2016; 98-B(1 Suppl A):6-9.

Ready to submit your research? Choose BMC and benefit from:

- fast, convenient online submission

- thorough peer review by experienced researchers in your field

- rapid publication on acceptance

- support for research data, including large and complex data types

- gold Open Access which fosters wider collaboration and increased citations

- maximum visibility for your research: over $100 \mathrm{M}$ website views per year

At $\mathrm{BMC}$, research is always in progress.

Learn more biomedcentral.com/submissions 